\title{
Revival of Tubular Structures for Contemporary
}

\section{Supertall Buildings}

\author{
Kyoung Sun Moon \\ Yale University School of Architecture
}

\begin{abstract}
Tubular systems developed in the 1960s opened a new era of supertall buildings with more efficient structures. Many tall buildings in the 1970s and 1980s were structured with tubular systems. Despite its inherent structural efficiency in carrying lateral loads, however, use of the tube system decreased in the following decades. In recent years, however, tubular structures in their original forms, modified forms and combined forms with other systems are widely used again for supertall buildings throughout the world. This paper reviews the resurgence of tubular structures for contemporary supertall buildings and studies their further potential.
\end{abstract}

Keywords: Tall buildings, tubular structures, framed tubes, bundled tubes, braced tubes, braced megatubes, diagrids.

\section{Introduction}

Iron/steel skeletal structures developed in the late 19th century enabled the emergence of tall buildings. The system evolved to the moment resisting frame with braced interior core and was employed for numerous tall buildings, including the 381 $\mathrm{m}$ tall Empire State Building of 1931, until the development of tubular structures in the late 1960s and 1970s. Unlike the conventional system, the tubular system places major lateral load resisting components on the perimeter of the building. Therefore, the structural depth of the system is maximized to carry lateral loads most efficiently.

As a newly developed concept providing more efficient structures for tall buildings, various tubular systems were widely used for major tall buildings throughout the world until the 1980s. Architectural potential of the tubular systems were also rigorously explored as were the cases with the demolished One and Two World Trade Center in New York, John Hancock Center and Sears Tower both in Chicago. The 
framed tube, braced tube, and bundled tube systems were employed for these supertall buildings, respectively. However, as the tubular concept substantially influenced the façade design of tall buildings due to its configurational characteristics, its uses decreased in the following decades in pursuit of more flexibility in design.

Tubular structures are still one of the most efficient structural systems for tall buildings. In recent years, various tubular systems in their original forms, more efficiently modified forms, new forms, and combined forms with other structural systems are widely used again for contemporary supertall buildings throughout the worlds. This paper reviews the recent revival of tubular structural systems and investigates their further potentials.

\section{Framed Tubes for Residential Towers}

Though framed tubes developed in the 1960s were used as a very efficient structural system for many tall buildings of the 1970s and 1980s, they were not widely used during the following decades because of their configurations involving very narrowly spaced perimeter columns that obstruct views and govern the façade design significantly. However, framed tubes are employed again for some of the recent supertall residential towers, such as the $426 \mathrm{~m}$ tall 432 Park Avenue in New York and $445 \mathrm{~m}$ tall Marina 106 in Dubai. While tall buildings were predominantly commercial office towers until even the late 20th century, beginning from the 21st century the number of residential towers has been significantly increasing. And for residential tall buildings whose floors are typically composed of many separate rooms, smaller perimeter openings of the framed tube system could be well integrated with the floor plans and corresponding façade design.

In fact, the revival of framed tubes in conjunction with ever-increasing residential supertall buildings in recent years typically produces tube-in-tube structures because these buildings usually have reinforced concrete cores that structurally perform as inner tubes. The 432 Park Avenue is composed of $9 \mathrm{~m} \times 9 \mathrm{~m}$ core tube and $28.5 \mathrm{~m} \times$ $28.5 \mathrm{~m}$ perimeter framed tube both in reinforced concrete. Additionally, there are outriggers between these tubes at five vertical locations around the five mechanical levels of two-story height. Furthermore, in order to disturb organized alternating vortex-shedding, which can cause serious vibration problems, over the height of the building of a very slender rectangular box form, the perimeter framed tube is not enclosed at the five mechanical levels of two-story height (Figure 1). 


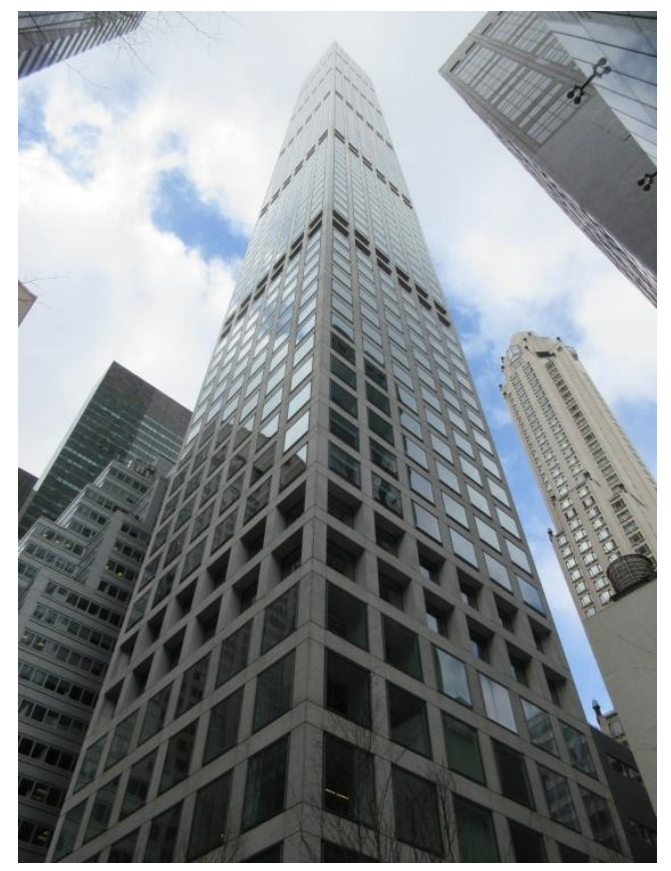

Figure 1. 432 Park Avenue

The tube-in-tube structural system could even further be developed into bundled tubes if it is well integrated with residential plan layouts composed of multiple small spaces. The bundled tube system with its reduced shear-lag is a very efficient structural system for supertall buildings. However, the bundled tube system ends up with interior columns that diminish flexibility in interior space layouts and consequently the system is perhaps not that desirable for today's office spaces. In residential towers, however, the bundled tube system with interior columns and/or walls could potentially be well integrated with demising walls/columns defining various residential functions.

\section{Diagrids for Non-Orthogonal Aesthetics}

The effectiveness of including diagonal bracings in resisting lateral forces was well recognized from the early designs of tall buildings in the late $19^{\text {th }}$ century. However, the aesthetic potential of the diagonal bracings was not explicitly appreciated. Thus, diagonals were generally embedded within the interior cores. A major departure from this design approach occurred when braced tube structures were introduced in the late 1960s. For the 100-story tall John Hancock Center in Chicago, the diagonals were 
located over the entire perimeter surfaces of the building in order to maximize their structural effectiveness and capitalize on the aesthetic innovation. The expressive braced tube system in its original form with perimeter columns and large diagonal bracings is not much used today. However, a new form of tubular structures with only perimeter diagonals more densely placed as diagonal grids - diagrids - is prevalently used for today's tall buildings.

The difference between braced tube and diagrid structures is that, for diagrid structures, all the conventional vertical perimeter columns are eliminated. This is because the diagonal members in diagrid structural systems are configured to carry gravity loads as well as lateral forces, whereas the diagonals in conventional braced tube structures are designed to primarily carry lateral loads. Compared with conventional framed tubular structures without diagonals, diagrid structures are much more effective in minimizing lateral shear deformations because diagrids carry shear by axial action of the diagonal members, while framed tubes carry shear by the bending of the perimeter columns and beams.

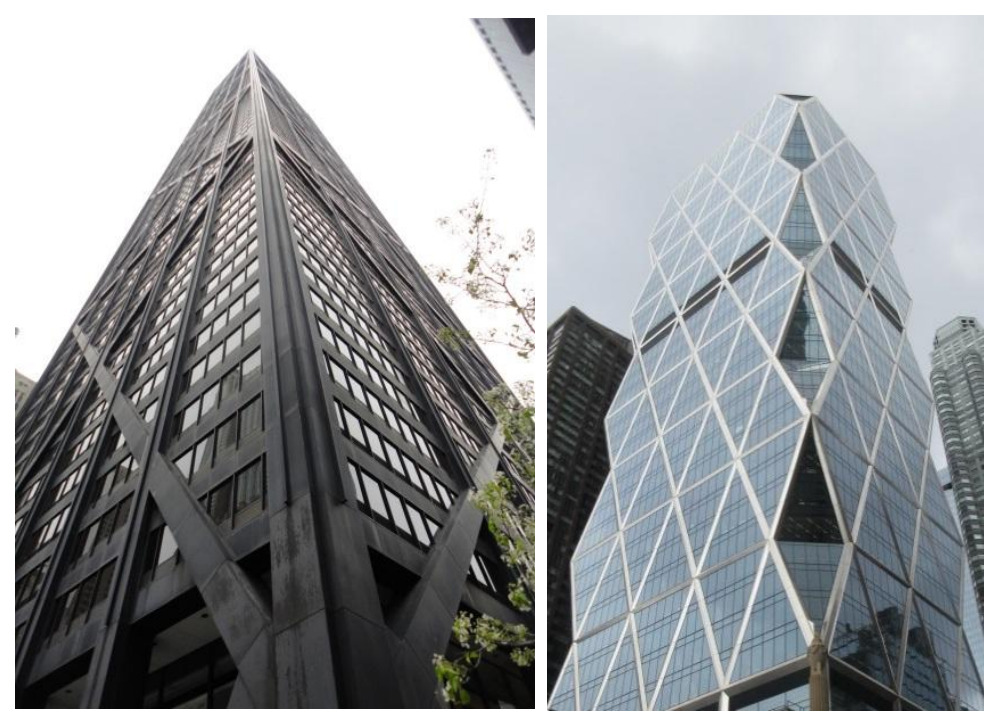

Figure 2. Braced tube (John Hancock Center) vs. diagrids (Hearst Tower)

Many diagrid buildings have been built throughout the world since the most expressive Hearst Tower of 2006 in New York. A diagrid angle of about 70 degrees is consistently used throughout the diagrid portion of the structure, and these uniform angle diagrids are boldly expressed on the building façade. The Hearst Tower worked 
as a prototype of many successors of uniform angle diagrids. The $439 \mathrm{~m}$ tall 103-story Guangzhou International Finance Center is the tallest diagrids at this time and it can be considered as a uniform angle diagrids though there are some slight angle changes over the height due to the gently tapered form of the building.

Diagrids can also be designed with logical angle variations along the height of the building for very tall and slender towers. Simultaneously considering load carrying mechanisms of gravity, overturning moments and lateral shear forces, the best strategy is using gradually steeper diagrid angles toward the base of the building (Moon, 2008; Baker et al, 2009). The unbuilt $555 \mathrm{~m}$ tall 112-story Lotte Super Tower project by SOM is a good example of vertically varying angle diagrids. If a constant diagrid angle is desired, a uniform angle a little steeper than 70 degrees should be used because this building is much taller and slenderer than the Hearst Tower. Instead of using a uniform angle, however, vertically varying angle diagrids were proposed in order to maximize the structural efficiency of the system. An angle of about 78 degrees was used in the lowest diagrid modules and that of about 60 degrees was used in the highest diagrid modules.

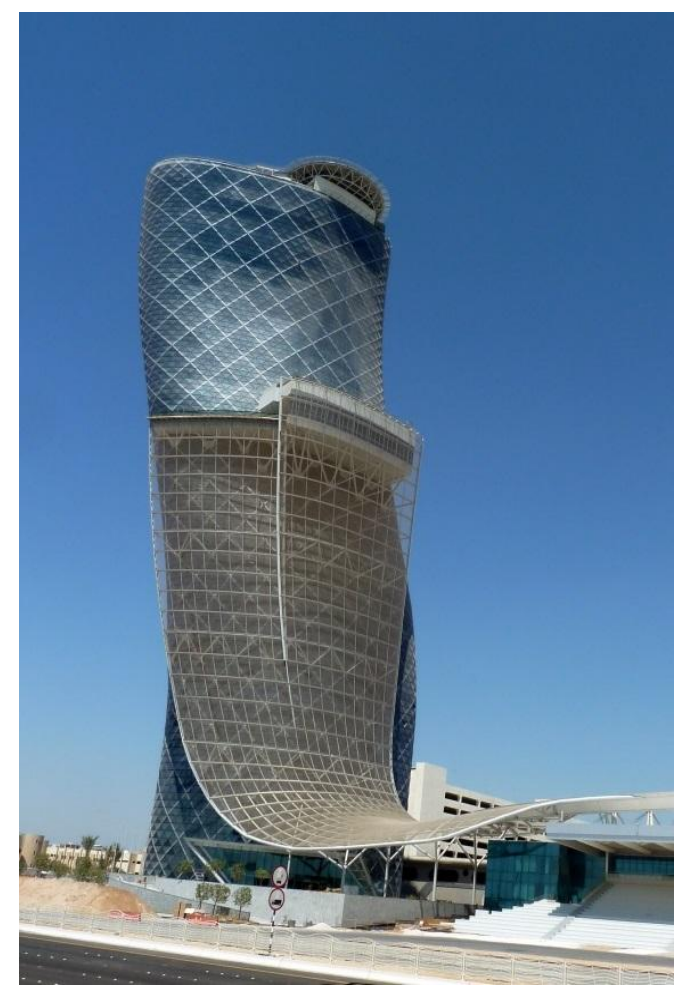

Figure 3. Capital Gate Tower 
In addition to the inherent structural efficiency of the system, another major advantage of the diagrid system is related to the prevalent emergence of complex-shaped tall buildings in this era of pluralism in architectural design. The system is well suited to recent complex-shaped tall buildings especially for freeform towers such as the Capital Gate Tower in Abu Dhabi because freeform geometry can be better defined with triangular planes naturally produced by diagrids without distortions.

\section{Braced Megatubes for Megatall Buildings}

Among the framed, braced and bundled tube systems, the braced tube system with large perimeter diagonals is the most efficient one in general (Moon, 2014). As envisioned by Fazlur Khan as "the ultimate possible improvement of the structural efficiency (Khan, 1972)," and proposed also by William LeMessurier for his theoretical study of the 207-story tall Erewhon Center (Rastorfer, 1985), the best column arrangement in a square floor plan of a tall building is four large corner columns with $X$ bracings between two corner columns on the same side to provide maximum lateral stiffness.

This idea of a modified braced tube with corner megacolumns and a reasonably good solution on the gravity system has been employed for recent supertall buildings and is classified as braced megatubes in this paper. In the $597 \mathrm{~m}$ tall 128-story Goldin Finance 117 currently under construction in Tianjin, four corner megacolumns in conjunction with large perimeter braces carry lateral loads very efficiently. In terms of carrying gravity loads, there are additional small gravity columns between the corner megacolumns. The gravity loads on these gravity columns are transferred to the megacolumns through the belt trusses installed between the megacolumns at every about 15 stories in relation to the module height of the perimeter $\mathrm{X}$ bracings.

While the arrangement of corner megacolumns establishes one of the most efficient lateral load resisting systems, it is obstructive for viewing, particularly impacting valuable interior corner spaces of the building. In the $528 \mathrm{~m}$ tall 108-story Citic Tower (formerly known as China Zun Tower), also currently under construction in Beijing, a very similar structural concept was used. However, the corner megacolumns of the Citic Tower are split into two following the rounded square-shaped floor plans, providing column-free corner space. Though this configuration with paired megacolumns around the corners does not provide the same level of stiffness 
provided by single corner megacolumns when the same amounts of structural materials are used, it produces more desirable architectural result. The configuration of the gravity columns and transfer belt trusses in the Citic Tower is very similar to that in the Goldin Finance 117.
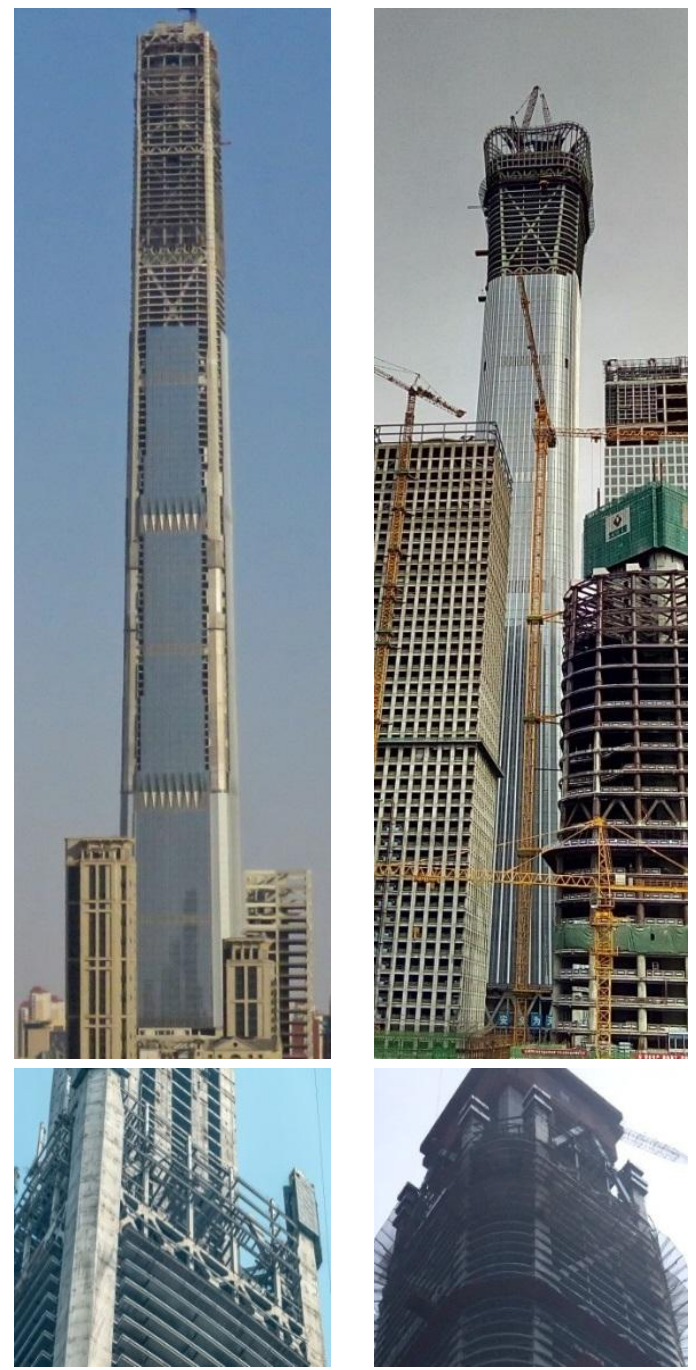

Figure 4. Goldin Finance 117 and Citic Tower under construction

Braced megatubes are also used in combination with other systems. When it is combined with an outrigger system, the combined system becomes a mixed system with the megacolumns shared by the both braced megatube and outrigger systems. The braced megatube can also form a tube-in tube system in combination with an 
interior core tube. As one of the most efficient structural systems for tall buildings, it is expected that uses of the braced megatube of various forms will keep increasing for future megatall buildings.

\section{Conclusions}

While tubular structural systems reopened the era of supertall buildings in the late 1960s and early 1970s and were widely used until the 1980s, their uses decreased in the following decades. However, in conjunction with the significant increase of residential tall buildings in recent years, framed tubes well integrated with residential functions are employed again for residential supertalls. Instead of typical braced tubes that once led the structural expressionism, diagrid systems with their distinguished non-orthogonal aesthetics and similar level of structural efficiency are widely used today. Another variation of the conventional braced tube is the braced megatube. By employing corner megacolumns, the efficiency of the braced tube system is maximized in the braced megatube. It is expected that the revival of tubular structures will continue with their inherent structural efficiency and today's architectural design trend of pluralism accepting a vast range of design concepts.

\section{References}

Ali, M. M., 2001. Art of the Skyscraper: The Genius of Fazlur Khan, Rizzoli International Publications, New York, NY.

Ali, M. M. and Moon, K., 2007. "Structural Developments in Tall Buildings: Current Trends and Future Prospects," Architectural Science Review Journal, Vol. 50.3, pp. 205-223.

Ali, M. M. and Moon, K., 2018. "Advances in Structural Systems for Tall Buildings: Emerging Developments for Contemporary Urban Giants," Buildings, 2018, 8(8), 104; doi: 10.3390/buildings8080104.

Baker, W., Besjak, C., McElhatten, B., and Biswas, P., 2009. "555m Tall Lotte Super Tower, Seoul, South Korea," Proceedings of Structures Congress, Austin, TX, April 30 - May 2.

Boake, T.M., 2014. Diagrid Structures: Systems, Connections, Details, Birkhauser Verlag, Basil, Switzerland.

Connor, J.J., 2003. Introduction to Structural Motion Control. New York: Prentice Hall.

Council on Tall Buildings and Urban Habitat (СTBUH), 2015. 100 of the World's Tallest 
Buildings. Images Publishing Group, Mulgrave.

Council on Tall Buildings and Urban Habitat, 2015. Tall Buildings of China. Images Publishing Group, Mulgrave.

Katz, P. and Robertson, L.E., 2008. "Case Study: Shanghai World Finance Center," CTBUH Journal: International Journal on Tall Buildings and Urban Habitat Journal, Issue II, pp. 10-14.

Khan, F.R., 1972. "Influence of Design Criteria on Selection of Structural Systems for Tall Buildings," Proceedings of the Canadian Structural Engineering Conference. Toronto: Canadian Steel Industries Construction Council.

Liu, P., Ho, G., Lee, A., Yin, C., Lee, K., Liu, G., and Huang, X., 2012. "The Structural design of Tianjin Goldin Finance 117 Tower," International Journal of Hi-Rise Buildings. Vol.1-4, pp 271-281.

Liu, P., Luo, N., Whitlock, R., and Lei, L., 2014. "Case Study: China Zun Tower, Beijing," CTBUH Journal: International Journal on Tall Buildings and Urban Habitat Journal, Issue III, pp. 14-20.

Moon. K., 2010. "Stiffness-Based Design Methodology for Steel Braced Tube Structures: A Sustainable Approach," Engineering Structures, Vol. 32, pp 3163-3170.

Moon, K., 2014. "Comparative Efficiency of Structural Systems for Steel Tall Buildings," International Journal of Sustainable Building Technology and Urban Development. Vol.5-3, pp 230-237.

Rastorfer, D., 1985. William J. LeMessurier's Super-Tall Structures: Architecture-Engineering, Architectural Record, Vol. 173.2, pp. 150-157.

Schueller, W., 1990. The Vertical Structure, Van Nostrand Reinhold, New York, NY. 